\title{
Microlearning in teaching English to students of engineering specialities
}

\author{
Olesya Tolstikh ${ }^{1 *}$, Victoria Pankova ${ }^{1}$, and Evgenia Krasnova $^{2}$ \\ ${ }^{1}$ Moscow Russian University of Transport (MIIT), 127055, Moscow, Russia \\ ${ }^{2}$ Don State Technical University, 344002, Rostov-on-Don, Russia
}

\begin{abstract}
The article aims to synthesise researches on technology-based microlearning in teaching. The key themes emerged: microlearning methods of information delivery and principles; the impact of microlearning on students outcomes. The platform MS Teams described as the basis for the introduction of the technology into the process of teaching English to engineering specialities. The results of the technology application were described.
\end{abstract}

\section{Introduction}

The impact of globalisation to the contemporary system of higher education cannot be underestimated. Students, graduating from the university with their bachelor's degrees, tend to continue their studies abroad looking for their particular specifications, or seek positions of engineers in highly developed organisations, working in cooperation with oversea companies. Consequently, the social demand to the level of English of non-linguistic specialities increases, meaning that knowledge of general English per se is not enough anymore, bringing us to the necessity of teaching professional language. On the other hand, our educational society faces the problem: the English language is not regarded as an entrance exam to technical specialities, and the level of it is rather diverse between students. Thus, learning professional language can become a challenge for some of freshmen. Obviously, an intensive correction course may be helpful to even the knowledge of the general English language. Considering that the amount of workload, for students as well as the teachers, is incredibly high, the additional course cannot be included into the curriculum, but can be based on the intensive and skilful use of information and communication technologies (ICT).

The purpose of this article is to analyze and summarize the methodological and pedagogical researches of Russian and foreign authors concerning the questions of microlearning in general and teaching languages in particular, as well as describe the experience of using MS Teams as a platform to implement microlearning technology in the educational process by tutors of the "Russian and foreign languages" chairs, RUT (MIIT).

In the context of the course, developed by the chair members, several urgent objectives were solved:

- the use of elements of the microlearning technology;

*Corresponding author: om.tolstikh@gmail.com 
- providing students with additional materials;

- implementation of test online;

- completion of tasks for drilling practice-oriented receptive activities online.

\section{Materials and methods}

In the contemporary teaching environment the concept of microlearning is widely used. Although, having been used in the pedagogy for no less than 20 years, the phenomena is nowadays discussed through the prism of mobile, distance, computer-basedlearning. The idea of microlearning originates from the programmed or automated education which was proposed by B.F. Skinner in 1954 and later developed by N.A. Crowder, known for his branching algorithm. The distinctive characteristics of programmed learning are the following:

- the division of teaching materials into short logically complete parts;

- the information is introduced in an orderly manner;

- correct responses can be rewarded and incorrect ones must be explained once again and drilled;

- all responses should receive instant feedback.

Students proceed from one step to another until they complete the programme.

Though this conception by Skinner has been developed by many researchers, it is considered to be an evolutionary development stage of e-learning nowadays. The following key principles may be considered essential in implementing the concept into the microlearning teaching technology.

1. The principle of short steps

2. The principle of immediate confirmation

3. The principle of self-pacing.

4. The principle of student testing.

The review of sources on the topic showed that there is no universally accepted definition of microlearning technology. Consequently, it is paramount to introduce our understanding of microlearning: it is an approach which deals with small logically complete learning units which are introduced on regular short-term basis and drilled through learning activities. Microlearning processes often derive from interaction with micro-content, which takes place either in designed (media) settings (e-learning) or in emergent micro-content structures like.

Nowadays, in the era of digitalisation and high development of media, the task of catching our students attention is rather hard, but making them keep their concentration on what they are doing is absolutely laborious. This is the result of the fact, that young adults, being members of digital generation, tend to get information through social media such as VK, Facebook, Instagram, Twitter etc., where it is presented in a short concise manner. Consequently, students are inclined to read short pieces of information and skip or scroll down long texts. Though initially it was the matter of focusing on crucial things, not to overload mind with extra superfluous information, nowadays, it is the question of grasping the information which seems to be interesting at first sight no matter how important or useless it may turn out to be eventually. This disadvantage may be used to help us implement the correction microlearning course into the educational process. The concept of microlearning is to incorporate those micro steps in educational digital environment on the daily basis, creating a routine.

It is crucial that students keep doing daily microlearning activities. The implementation of the technology can be compared to the process of habit formation.

Habit-formation advice, paired with a 'small changes 'approach, has been tested as a behaviour change strategy within the developed course. It is essential at the starting point to 
give students single specific actions in a consistent context. It is absolutely different from different types of activities. Variations at the step will surely stave off motivation and develop confusion. Here students should choose the target behaviour themselves. Most often that may be done according to the preferable signal of information perception.

Thus, it may be quite clear that the groups of visual and auditory learners, following their name, perceive information through their vision or auditory sensations. As for kinaesthetic learners it is highly important to show them practical binding of the rule to the real life. The basic type of introducing information to digital or discrete learners is logical organisation which will enable the rational channel of perception.

Having combined the main principles of microlearning concept and the four types of information perception we considered to base our correction course on the following principles:

- Auditiveness. All the lecture should be in audio format: that may be screencasts, audio podcasts, which on the one hand is better perceived by those who tend to be visuals, on the other hand, students have some feeling of the tutor's presence, hearing his voice or him in person.

- Visibility. All the materials should be accompanied with additional visual aid for better commitment into students' memory.

- Modular teaching. Each module is divided into a shorter block of information, which enhances its memorisation.

- Conciseness. Being an analytical language, most rules of the English language may be introduced in the form of algorithms, mind maps, tables, schemes etc. Having studied scientific researches on the matter of recent years and conducted an empiric study, we inferred that different ICT may be assigned to the above mentioned psycho-physical type of information perception:

- Auditory learners: podcasts, as well as screencasts, invitations to discuss studied materials in forums, online discussions, chat rooms.

- Visual learners: photos or screenshots, infographics or graphs, tables or drawings .

- Kinesthetic learners: a learning path build through the whole course of learning with detailed explanation of objectives.

- Digital learners: mind maps, infographics, instructions, reasoning in the text.

Not to overload the mind work of students, while creating our correction course, we followed Miller's law, according to which students' can hold seven objects or pieces of information in their immediate memory. Moreover, due to the above mentioned tendency of surfing social networks, experts found out that that the human attention rate has declined to $8 ю 25$ seconds. So, following the forgetting curve by Hermann Ebbinghaus, the fragments of information and drilling repeated in 30 minutes, in a day students were offered the same theory but a new drilling exercise. The next drilling was due next day; the revision was due in two weeks. And the final drilling exercise was introduced in 2 months. To achieve that we needed the form a habit of doing those daily exercises. So, the first month students got approximately the same type of exercises, which on the one hand, developed their language skill, on the other kept their motivation and formed the habit of learning the language on daily basis. Though the habit is formed in 22-30 days, we cannot achieve any significant result introducing simple microlearning activities. So, gradually the information and exercises sent to students varied to keep forming the habit and still work on different types of language aspects and tasks.

As far as, the selection of micro learning activities and individual pace and time-limits are highly important for didactical designs, we conducted a pre-experiment survey, including questions concerning students' preferable amount of learning activities, timing, preferable period of the day for such activities, which is essential, as tasks sent to students during their study period at the university lead to skipping them, and amount of time, spent 
to do one individual activity, preferable platform (where students were offered a range of platforms MS Teams, Google Class, Edmodo, each of which is enriched with additional services. It should be highlighted that we did not contact any test to detect the psychophysical type of information perception as far as the whole course intended to include various formats of theory presentation meeting the requirements of all types of students.

While developing the course we had to deal with several highly important questions concerning the organisation of the educational process:

- $\quad$ the number of micro sessions per day;

The survey we conducted showed that students, willing to catch ups with their gaps, overestimated their abilities, stating that wanted to have about 10 sessions a day. Experimentally we proved that no more than 3 sessions had to be done, otherwise students skipped the exercises for later and missed the deadlines.

- the timing - according to literature study microlearning can span from a minute up to fifteen minutes or even more.

- the period of the day and whether weekends should be included;

- deadlines: setting up deadlines kept students active without leaving all the tasks or exercises for doing later;

- the type and amount of learning activities;

- revision and consolidation frequency;

- feedback organisation;

- the structure of each microlearning activity;

- the platform to conduct the experiment;

Each micro learning activity included short instruction on how to do the task or explanation of theory; in cases of grammar and vocabulary in use a drilling exercise was given; reading and listening activities contained a short text for for reading and comprehension tasks according to the type of reading skill developed.

Examples of activities

- reading a paragraph or a short text;

- listening to a podcast;

- watching a short video;

- viewing flashcards;

- commiting topical vocabulary into memory through practice;

- multiple choice exercises;

- fill in the gaps exercises;

- online educational micro-games

- composing short sentences with topical vocabulary.

The students of the same level were sorted into groups. This way students of different specialities turned out to participate in the same correction course. So, it is difficult to make a timetable for meetings and discussions. But all students always carry their smartphones, tablets or laptops. Ms Teams works as a bases for the communication with the students and sending them assignments and tests.

- MS Teams was chosen due to the fact that it combines MS Services and additional online services and they may be posted in one place. That means that students will not get distracted by some social network posts while doing or reading the given information and tasks. 
- The image of the task proved to be the following: the topic of studying during the session, general topic, time necessary to study the given theory, time necessary for studying additional sources, time for practice, explanation of the task; forum for questions.

- The organisation

\section{Experiment}

The process of teaching English and implementing a correction course for students of RUT (MIIT) was based on the combination of classroom training and applications and services provided by Microsoft. Due to the development of modern technologies, to be exact digital devices, students had the opportunity to apply mobile technologies (mobile devices: phones, tablets), which contributed to the continuous learning process. MS teams is a highly developed system which allows to contact the students quickly enough; on sending each assignment they get a notification showing the name of the task and the deadline. For completing the tasks students gained points.

During the course the students were offered to participate three daily sessions during weekdays, each of which contained one type of lecture explaining a theory chunk, a drilling exercise. The number of sessions on daily bases was chosen due to the experiment conducted. Firstly, seven drillings were impossible to organise due to the timetable of students. And as far as it was essential to form a habit, we did not want the students to keep all the exercises to be done later. The second hypothesis included five sessions per day, which were scheduled for two morning drillings and three afternoon drillings. The first week of the conducted experiment showed that student manage the tasks quite easily and willingly without delays, the following weeks the motivation faded as in general students spent about an hour developing their skills in English and later gradually they left their exercises behind being in need to do tasks in their professional sphere.

As we have already mentioned above, students were given instructions or theory, which was presented as a short information lecture with rules to be understood and memorised, or a revision mini-lecture, focused on summarising the whole block. The lectures could be introduced in different forms: a screencast, a mind map, a text with chain reasoning.

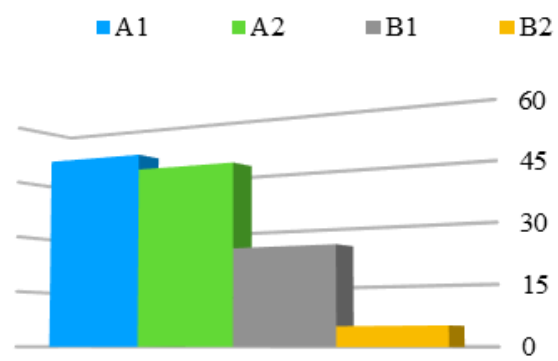

Fig. 1. The level of English of engineering specialities students (pre-experiment)

Each screen cast lasted no longer than 3 minutes with explanation of one piece of information. Then students were given drilling exercises such as fill in the gap, using the correct form of the word, multiple choice etc.

It should be noted that drilling exercises in grammar should be varied so that within a day students could practice new rules of the day and revise something learnt before.

Reading practice included short texts mostly devoted to engineering topics. The session consisted of one pre-reading exercise for students to get ready for the task, a text with 
topical vocabulary at the right side of the page to help them while reading, and an exercise of multiple choice, matching or fill in the gaps, depending on the objective of the task. Though the type of exercise was familiar to the students, it is essential to include a detailed interaction before the task.

Listening practice turned out to be weakest point of the whole experiment. Experimentally, we proved that this task was ignored by the participants in the morning hours and organised to the evening introduction, when still it was ignored by many of the participants. So, this level of attention to the activity was explained by the students that they most often did their practice on the route or at the university, where it was not convenient to listen to the audio, while the evening timing was a little better.

Vocabulary practice ....

At the beginning of the experiment one hundred twenty eight students had an introductory test in reading, listening, vocabulary and grammar. The general level of English of the participants varied from A1 to B2 (fig.1). All students were offered having a supplementary course of the language based on microlearning. Thus, we had one hundred twenty eight trainees.

Table 1. The general timetable was the following

\begin{tabular}{|c|l|l|l|l|l|}
\hline $\begin{array}{c}\text { Session } \\
\text { time }\end{array}$ & \multicolumn{1}{|c|}{ Monday } & \multicolumn{1}{|c|}{ Tuesday } & \multicolumn{1}{|c|}{ Wednesday } & \multicolumn{1}{|c|}{ Thursday } & \multicolumn{1}{|c|}{ Friday } \\
\hline $8.40-9.00$ & Reading & Vocabulary & Grammar & Vocabulary & Grammar \\
\hline $\begin{array}{c}15.00- \\
15.30\end{array}$ & Grammar & Grammar & Reading & Grammar & Vocabulary \\
\hline $\begin{array}{c}18.00- \\
18.30\end{array}$ & Listening & Reading & Listening & Reading & Listening \\
\hline
\end{tabular}

As you may see in the table № 1 within one week the participants had fifteen sessions in general:

- grammar: an introduction of a new rule or consolidation of a familiar one and a drilling exercise.

- vocabulary: words with definition and translation, collocations which were practises in the service Quizlet and and exercise on multiple choice, matching or cloze.

- listening: in the introductory part of the session, the type of the exercises was explained. There were the following types of listening in the course:

- listening for gist;

- listening for specific information;

- listening for details;

- inferential listening

- After listening students were given different types of exercises, such as

- ticking the items;

- multiple choice;

- ordering actions;

- true and false questions;

- filling the gaps.

- Reading is also included an introductory part with information of the activity objective and the reading technique There were the following modes of reading in the course:

- Skimming is reading rapidly in order to get an overview of the text, where students focus on the main idea of the text; 
- Scanning - is a quick reading to find specific information in the text;

- Reading for detail - where students should understand not only the content of the text, but its significance as well.

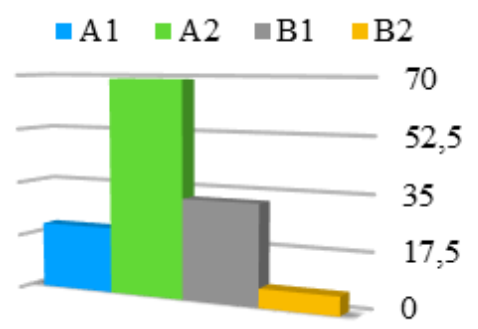

Fig. 2. The level of English of engineering specialities students (results)

It should be noted here that as far as the modes of listening and reading are approximately similar, within one day students were given tasks on different modes.

The main platform for the whole course was chosen the system MS Teams, including MS services. Most tasks for most activities were created in MS Forms. The results achieved by the students were immediately transferred into the MS Teams grading system. To add competitive spirit to the educational process at the end of each module in grammar or vocabulary, students were offered a game of Kahoot. Though the service is embedded into MS Teams, the results should be transferred manually into the grading system of the course. For video lectures, screen casts and listening tasks we used the original service MS Stream. The main convenience of the service was in the possibility to embed MS Forms tests into the video itself. This way the video could be paused in the middle, in case of necessity, and a question asked.

MS Teams offers an opportunity to divide students into groups by creating different channels in one team. Though we did not develop communicative skills (writing or speaking), we created forums in channels, dividing them into aspects grammar, listening, reading and vocabulary, where students could ask their questions and have discussion in English. Though the type of discussions was asynchronous, we still consider it to be most effective as the participants are not dependent geographically and have enough time to participate in the discussion. Moreover, many students were willing to answer their peers questions, which definitely improved their understanding of the material and developed their communicative skill.

\section{The results of the experiment}

The greatest challenge was to understand the amount of assignments to give daily, so that students were not overloaded with tasks and did not skip them. The results achieved so far, that the language level of students is improving gradually. The summative assessment conducted at the end of the course showed the changes in the general students's level of the language.

It should be noted though, that the essential part of the course was setting deadlines as without them students left all the tasks till the last day (weekend) and the objective of the experiment could not be fulfilled.

The second challenge was to define the amount of information given within one session. Though in literature it is states that one session may last up to 15 minutes, we considered that the timing depended on the day of the week, the information sent and the level of the language. Secondly, it was paramount to keep the information gap 20/80 not to make the frame too tiresome. 


\section{Conclusions}

We would like to note that the level of modern technology development offers a huge number of e-learning models. Nevertheless, our experience shows that the most effective use of technology is obtained with a competent methodological construction of the learning process and taking into account the principles and peculiarities of the microlearning technology. We consider, the article may be of interest to scientific and pedagogical workers of educational institutions planning to use information and communication technologies in the educational process.

\section{References}

1. B. Aitchanov, A. Satabaldiyev, K. Latuta, Journal of Physics: Conference Series 423, 1-4 (2013)

2. E. Alqurashi, Self-Efficacy in Online Learning Environments: A Literature Review. Contemporary Issues in Education Research (CIER) 9(1), 45-52 (2016)

3. M. Bothe, J. Renz, T. Rohloff, C. Meinel, 2019 IEEE Global Engineering Education Conference (EDUCON), 280-288 (2019)

4. P.A. Bruck, L. Motiwalla, F. Foerster, 25th Bled eConference (2012)

5. A. Bozkurt, E. Akgün-Özbek, O. Zawacki-Richter, International Review of Research in Open and Distributed Learning: IRRODL 18 (5), 118-147 (2017)

6. P. Brebera, European Conference on E-Learning, 85-93 (2017)

7. T. Dingler, D. Weber, M. Pielot, J. Cooper, C.-C. Chang, N. Henze, Proceedings of the 19th International Conference on Human-Computer Interaction with Mobile Devices and Services, 1-12 (2017)

8. S. B. Fountain, K. E. Doyle, Encyclopedia of the Sciences of Learning, Springer US 1814-1817 (2012).

9. L. Liu, K. Liu, J. Zhao, 2018 Seventh International Conference of Educational Innovation through Technology (EITT) 16-22 (2018)

10. Zhang Ruijuan, Application of "Micro Learning Resource" and "Flipped Classroom" in College English, Teaching, Technology Outlook (31), 150-151 (2015)

11. Z.Wang, Y. Luo, Y. Qu, International Journal of Innovation and Research in Educational Sciences (4)2, 130-132 (2017)

12. A. Zhamanov, M. Zhamapor, Journal of Physics: Conference Series 423(1), (2013). doi: $10.1088 / 1742-6596 / 423 / 1 / 012028$

13. Z. Bezhovski, S. Poorani, The evolution of E-learning and new trends, Inform Knowl Manag6 (3), (2016)

14. A. Tagarelli, R. Interdonato, Proc IEEE/ACM Conf. Advances in Social Networks Analysis and Mining (ASONAM) 215-222 (2013)

15. Shum H. Yeung, He X. Dong, Li D., From Eliza to Xiaolce: challenges and opportunities with social chatbots Frontiers of Information Technology and Electronic Engineering, Zhejiang University (2018)

16. M. Alemi, Sarab Anani, R., Z. Lari, International Education Study Journal 5(6), (2012)

17. D. Edge, S. Fitchett, M. Whitney, J. Landay, Proceedings of the 14th international conference on Human-computer interaction with mobile devices and services companion. 2012, ACM: San Francisco, California, USA193-194 (2012) 
18. Elena Bogatskaya, Svetlana Nevolnikova, Evgenia Krasnova, 9th International Conference on Education and New Learning Technologies (EDULEARN17) 111-117 (2017)

19. O. Tabatabaei, Goojani A. Heidari, Cross-Cultural Communication 8(2), 47-55 (2012) 